\title{
Parasite Survey in Rastrelliger brachysoma (Short Mackerel) from Selected Fish Markets in Zamboanga City, Philippines
}

\author{
Romenick Alejandro Molina* \\ Senior High School Department, Zamboanga City State Polytechnic College
}

Received: June 25, 2020; Revised: September 28, 2020; Accepted: November 7, 2020

\begin{abstract}
Rastrelliger brachysoma (short mackerel) or locally known as kabalyas is one of the most commercially important small pelagic fish because of its low price in the market and a good source of protein. However, like other fish, $R$. brachysoma are also prone to parasites. Thus, this study aimed to conduct a parasite survey in $R$. brachysoma sold in selected public markets in Zamboanga City. This study provides a baseline data about parasites in $R$. brachysoma and promote public health awareness with the locals in Zamboanga City. The researcher collected a total of $60 \mathrm{R}$. brachysoma using purposive sampling. In the laboratory, gills, stomach and intestines were removed from the samples and subjected for microscopic examination. Images were taken and used for identification of parasites and verified by experts. Prevalence and mean intensity were computed for parasites. There were eight genera, and three of which were identified to the species level. Among which, the most prevalent were Dermocystidium sp. and Amyloodinium sp. while Cryptocaryon irritans, Schistosoma sp. and Echinorhynchus sp. were least prevalent. In terms of intensity, Dermocystidium sp. has the highest mean intensity while Schistosoma sp. has the lowest mean intensity.
\end{abstract}

Keywords: Mean Intensity, Parasites, Prevalence, Rastrelliger brachysoma

\section{Introduction}

Rastrelliger brachysoma (short mackerel) or locally known as kabalyas, is a species of mackerel in the family Scombridae. It is widely spread in the shallow waters of Southeast Asia (Collette et al., 2011). It is one of the most commercially important small pelagic fish because of its low price, serving as a high protein source and contributing significantly to the total income of families engaged in it (Ghazali et al., 2012).

In spite of the direct value of short mackerel, most people do not focus so much attention on the health status of $R$. brachysoma. $R$. brachysoma plays an important ecological role as host to a range of taxonomically diverse parasites that exhibit a wide variety of life cycle strategies (Indaryanto et al., 2015). Like other fishes, $R$. brachysoma is prone to parasitism, which is a common phenomenon in marine environments (Ruiz, 1991).

Parasites are used increasingly as indicators for the differentiation of marine ecology because parasitic fauna might show a distribution parallel to the host (Madhavi and Lakshmi, 2012). Parasites in fish have been a great concern since they often produce disease conditions in fish which will lead to reduced growth, increase in the fishes' susceptibility to other diseases as well as fish loss (Raissy and Ansari, 2012). Effects of parasitism in fish range from mild to severe depending upon the intensity and pathogenicity of the parasites. As a result, there is a great threat to the fish industry which may result in the failure of production, and some infected fish could be unsuitable for human consumption.

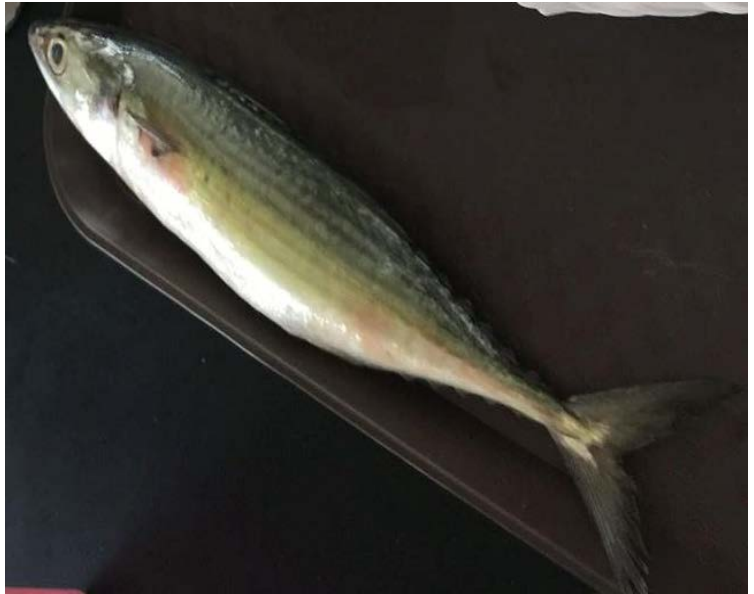

Figure 1. Rastrelliger brachysoma (Short Mackerel)

There were several studies conducted in investigating of fish parasites, and in the Philippines, it is being carried in freshwater fish. For instance, Salcedo et al. (2009), investigated the presence of parasites in Oreochromis niloticus (tilapia), Osphomenus olfax (gourami), Clarias batrachus (catfish), Ophiociphalus striatus (snakeheadfish), and Anabas testudineus (climbing perch) which were sold in Kabacan, Cotabato Public Markets.

In the case of $\mathrm{R}$. brachysoma, the only studies on describing Lecithocladium angustiovum (Digenea: Hemiuridae) and the community of helminths were conducted (Indaryanto, 2014; Indaryanto et al., 2015). Thus, this study aimed to conduct a parasite survey present in R. brachysoma sold in selected fish markets in

\footnotetext{
* Corresponding author e-mail: molina.romenick17@gmail.com.
} 
Zamboanga City. Thus, it will serve as a baseline data about fish parasites and promote public health awareness with the locals of Zamboanga City. This study focused on parasites which could be found in the gills, stomach and intestines of R. brachysoma.

\section{Material and Methods}

\subsection{Collection of Samples}

A total of $60 R$. brachysoma were purchased from selected fish markets in Zamboanga City and used in this study. Purposive sampling was employed, wherein only freshly caught $R$. brachysoma were selected. The samples were placed in a plastic bag with labels and placed in an ice chest. Samples were brought to the Biology Laboratory, College of Science and Mathematics, Western Mindanao State University, Zamboanga City.

\subsection{Microscopic Examination in Fish Samples}

To examine the internal organs for the presence of parasites, the fish were dissected by opening the abdominal cavity from the anus and anteriorly using dissecting tools. The gills of the fishes were scraped using scalpel and mixed with 10 drops of $0.8 \%$ saline water in a petri dish. A drop of the mixture was placed in a slide for microscopic examination. Prepared slides were examined under high power objective and low power objective using Photomicrograph. For the stomach and intestines of the fishes, they were removed and dissected for inspection. The stomach and intestines were scrapped with 10 drops of $0.8 \%$ saline water in petri dish. A drop of mixture was placed in a slide for microscopic examination under low and high power objectives using Photomicrograph.

\subsection{Staining and Identification}

Samples were preserved in Alcohol Formalin Acetic Acid (AFA). AFA was prepared by adding $5 \mathrm{ml}$ glacial acetic acid and $5 \mathrm{ml}$ formalin to $90 \mathrm{ml}$ 70\% ethyl alcohol. Samples on slides were stained with 1 drop of eosin solution. Eosin solution was prepared by adding 1 gram of Eosin Y, $5 \mathrm{ml}$ of glacial acetic acid to 1 liter of $70 \%$ ethyl alcohol (Echem at al., 2018). Images of the parasites were documented and were brought to Dr. Evelyn Campos of Zamboanga State College of Marine Sciences and Technology and Paul K. Aranton a Registered Medical Technologist for identification.

\subsection{Analysis of Data}

Prevalence and mean intensity of the parasites were computed using the formulas by Bush et al. (1997):

Prevalence $=\frac{\text { Total Number of Fish Infected with Specific Parasite }}{\text { Total Number of Fish Examined }} \times 100$
Mean Intensity $=\frac{\text { Total Number of Specific Parasite in the Sample }}{\text { Number of Infected Fish }}$

\section{Results}

\subsection{Identification of Parasites}

There were 8 parasites isolated and identified in $R$. brachysoma which include: Dermocystidium sp., Myxosporidia truttae, Amyloodinium sp., Cryptocaryon irritans, Encephalitozoon sp., Schistosoma sp., Kudoa thyrites and Echinorhynchus sp.
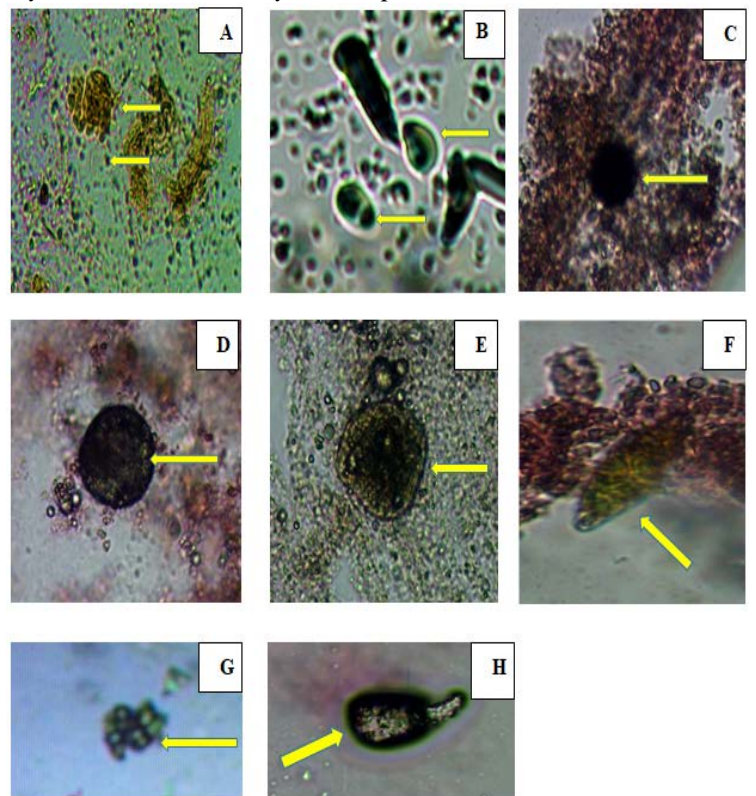

Figure 2. Identified Parasites in R. brachysoma at 100x magnification (A. Dermocystidium sp., B. Myxosporidia truttae, C. Amyloodinium sp., D. Cryptocaryon irritans, E. Encephalitozoon sp., F. Schistosoma sp., G. Kudoa thyrites and H. Echinorhynchus sp.)

\subsection{Prevalence and Mean Intesity of the Parasites}

Table 1 shows the computed prevalence of parasites in $R$. brachysoma. Result revealed that Dermocystidium sp. and Amyloodinium sp. were the most prevalent parasite with a prevalence value of $16.67 \%$. The second most prevalent parasite is Myxosporidia truttae with a prevalence value of $13.33 \%$, followed by Encephalitozoon sp. and Kudoa thyrsites with a prevalence value of $8.33 \%$ and $6.67 \%$, respectively. Cryptocaryon irritans, Schistosoma sp. and Echinorhynchus sp. were the least prevalent with a prevalence value of $5.00 \%$. Hence, there were only three (3) $R$. brachysoma where these parasites were spotted.

Table 1. Prevalence of Parasites in Rastrelliger brachysoma

\begin{tabular}{llll}
\hline Parasites & $\begin{array}{l}\text { Total } \\
\text { Number } \\
\text { Examined }\end{array}$ & $\begin{array}{l}\text { Total Number } \\
\text { of Infected } R .\end{array}$ & $\begin{array}{l}\text { Prevalence } \\
\text { brachysoma }\end{array}$ \\
\hline $\begin{array}{l}\text { Dermocystidium sp. } \\
\begin{array}{l}\text { Myxosporidia } \\
\text { truttae }\end{array}\end{array}$ & 60 & 10 & 16.67 \\
Amyloodinium sp. & 60 & 8 & 13.33 \\
$\begin{array}{l}\text { Cryptocaryon } \\
\text { irritans }\end{array}$ & 60 & 10 & 16.67 \\
$\begin{array}{l}\text { Encephalitozoon sp. } \\
\text { Schistosoma sp. }\end{array}$ & 60 & 3 & 5.00 \\
Kudoa thyrsites & 60 & 5 & 8.33 \\
Echinorhynchus sp. & 60 & 3 & 5.00 \\
\hline
\end{tabular}

Table 2 shows the computed mean intensity of parasites in $R$. brachysoma. Results revealed that Dermocystidium $s p$. has the highest mean intensity of 17.80. Myxosporidia truttae has the second highest mean intensity of 11.25 , followed by Echinorhynchus sp. (6.00), Cryptocaryon 
irritans (4.33), Kudoa thyrsites (3.50), Encephalitozoon sp. (2.80) and Amyloodinium sp. (2.70). Schistosoma sp. has the lowest mean intensity, with a value of 1.33.

Table 2. Mean Intensity of Parasites in Rastrelliger brachysoma

\begin{tabular}{llll}
\hline Endoparasites & $\begin{array}{l}\text { Total } \\
\text { Number of } \\
\text { Parasite }\end{array}$ & $\begin{array}{l}\text { Total Number of } \\
\text { Infected } R .\end{array}$ & $\begin{array}{l}\text { Mean } \\
\text { brachysoma }\end{array}$ \\
Intensity \\
\hline Dermocystidium sp. & 178 & 10 & 17.80 \\
Myxosporidia truttae & 90 & 8 & 11.25 \\
Amyloodinium sp. & 27 & 10 & 2.70 \\
Cryptocaryon irritans & 13 & 3 & 4.33 \\
Encephalitozoon sp. & 14 & 5 & 2.80 \\
Schistosoma sp. & 4 & 3 & 1.33 \\
Kudoa thyrsites & 14 & 4 & 3.50 \\
Echinorhynchus sp. & 18 & 3 & 6.00 \\
\hline
\end{tabular}

\section{Discussion}

The parasites isolated and identified in $R$. brachysoma were classified to their taxonomic groups into: fungi $(\mathrm{n}=$ 1), protozoans $(\mathrm{n}=5)$, trematode $(\mathrm{n}=1)$ and acanthocephalans $(\mathrm{n}=1)$.

Among the organs examined, the existence of parasites were found in gills and intestines only. In gills, Amyloodinium sp., Dermocystidium sp. and Cryptocaryon irritans were present. Amyloodinium sp. is a dinoflagellate that can be found on gills and skin of infected marine and estuarine fish that causes a powdery or velvety appearance. This kind of parasite can cause devastating disease which is known as marine velvet or amyloodiniosis that can lead to mortality of fish (Floyd and Floyd, 2011). Dermocystidium $s p$. contains a small spherical spore with a nucleus in the periphery and a prominent rectile body in the centre (Fujimoto et al., 2017). This can be found in gills, skin and cornea of the eye causing visible cysts of different sizes and shapes (El-Mansy, 2008). Cryptocaryon irritans is an obligate parasitic ciliate protozoan that causes white spot disease in marine fish. Furthermore, the presence of this protozoan can cause significant loses for aquarists and marine cultures in the world (Cardoso et al., 2019). The exposure of gills to the external water due to their respiratory activities causes the presence of these parasites (Bichi and Ibrahim, 2009).

In intestines, Myxosporidia truttae, Encephalitozoon sp., Schistosoma sp., Kudoa thyrsites and Echinorhynchus $s p$. were found. Myxosporidia truttae is a multicellular organism that is known for invading the tissues and organs of a fish, particularly the gall bladder. A normal gall bladder is characterized by a greenish hue. Infected gall bladder by Myxosporidia truttae turns its color into light pink (Fujita, n.d.). If the fish ingests the spores of Encephalitozoon sp., then the fish is infected. Encephalitozoon sp. are intracellular parasites with unicellular spores with an imperforate chitinous wall containing 1 sporoplasm and an elaborate hatching apparatus (Bruno, Nowk and Elliott, 2006). Schistosoma $s p$. or blood flukes live inside the blood vessels and are the only trematodes with separate sexes (Skelly, 2008). In this study, eggs of Schistosoma sp. were seen with terminal spines. $R$. brachysoma might ingested the eggs accidentally. Hence, fishes are not ordinary hosts in any of
Schistosoma species' life cycle. The typical life cycle of Schistosoma treamatode or its related species involves only two hosts, (a) a freshwater snail intermediate host and (b) either a mammalian or bird definitive hosts (Nelwan, 2019). Kudoa thyrsites is a microscopic parasite present in marine fish species worldwide. It produces an enzyme that can make fish flesh soft, commonly known as soft flesh (Whitaker and Kent, 1991). Echinorhynchus sp. are endoparasitic worms found in both freshwater and marine fishes worldwide that has a retractable probscis armed with rows of hooks used to attach in the intestines of fish. Infected fish is associated with irreversible damage on intestinal tract and tissue necrosis in areas where the worm is attached (Sakthivel et al., 2014).

Among the parasites, the most prevalent were Dermocystidium sp. and Amyloodinium sp. while Cryptocaryon irritans, Schistosoma sp. and Echinorhynchus sp. were least prevalent. In terms of intensity, Dermocystidium $s p$. has the highest mean intensity while Schistosoma sp. has the lowest intensity. Prevalence and intensity depends on many factors such as feeding habits of host and physical parameters such as salinity, quality of water, $\mathrm{pH}$ and temperature (Velasquez, 1984; Indaryanto et al., 2015).

\section{Conclusion}

There were eight parasites isolated and identified in $R$. brachysoma which can be found in the gills and intestines. In terms of prevalence, Dermocystidium $s p$. and Amyloodinium sp. were the most prevalent parasites while Cryptocaryon irritans, Schistosoma sp. and Echinorhynchus sp. were least prevalent. In terms of intensity, Dermocystidium $s p$. was the highest while Schistosoma sp. was the lowest.

\section{Conflict of Interest}

The author declares that there is no conflict of interest with this work and the preparation of the paper.

\section{References}

Bichi A and Ibrahim A. 2009. A survey of ecto and intestinal parasites of Tilapia zillii (Gervas) in Tiga Lake, Kano, Northern Nigeria. Bayero Journal of Pure and Applied Science, 2(1): 79-82.

Bruno D, Nowak B and Elliott D. 2006. Guide to the identification of fish protozoan and metazoan parasites in stained tissue sections. Diseases of Aquatic Organisms, 70: 1-36

Bush A, Lafferty K, Lotz J and Shostak W. 1997. Parasitology meets ecology on its own terms: Margolis et al. re-visited. $J$. Parasitol, 83:575-583.

Cardoso P, Soares H, Martins M and Balian S. 2019. Cryptocaryon irritans, a ciliate parasite of an ornamental reef fish yellowtail tang Zebrasoma xanthurum. Rev. Bras. Parasitol. Vet., 28: 4.

Collette B, Di Natale A, Fox W, Juan Jorda M, Nelson R. 2011. Rastrelliger brachysoma. The IUCN Red List of Threatened Species 2011: e.T170318A6745895.

Echem R, Barba H, Guangyao L, Peng F, Buenaventura N. 2018. Endoparasites in Chanos chanos (Forsskal, 1775) from the wetlands of Zamboanga City, Western Mindanao, Philippines. $J$ Aquac Res Development, 9: 535. 
El-Mansy A. 2008. A new finding of Dermocystidium- like spores in the gut of cultured Oreochromis niloticus. Global Veterinaria, 2: 369-371.

Floyd R and Floyd M. 2011. Amyloodinium ocellatum, an Important Parasite of Cultures Marine Fish. Southern Regional Aquaculture Center, 4705; 1-12.

Fujimoto R, Sousa N, Diniz D, Diniz J, Madi R, Martin, M, et al. 2017. Dermocystidium $s p$ infection in farmed hybrid fish Colossoma macropomum x Piaractus brachypomus in Brazil. Journal of Fish Diseases, 1-4

Fujita T. nd. Studies on Myxosporidia of Japan. Journal of the College of Agriculture, Hokkaido Imperial University, Sapporo, Japan, 10(7): 191-248.

Ghazali A, Abidin D, Nor S and Nalm D. 2012. Genetic variation of Indian Mackerel (Rastrelliger kanagurta) of Sabah water based on Mitochondrial D-loop Region: A Preliminary Study. Asian Journal of Biology and Biotechnology, 1(1): 1-10.

Indaryanto F. 2014. Community Structure of Helminth Parasites of Mackerel (Rastrelliger spp.) from Banten Bay and Pelabuhan Ratu Bay. Jurnal Ilmu Pertanian Indonesia, 19(1): $\quad$ 1-8.

Indaryanto F, Abdullah M, Wardiatno Y, Tiuria R and Imai $\mathrm{H}$. 2015. A description of Lecithocladium angustiovum (Digenea: Hemiuridae) in Short Mackerel, Rastrelliger brachysoma (Scombridae) of Indonesia. Tropical Life Sciences Research, 26(1): 31-40.

Madhavi R and Lakshmi T. 2012. Metazoan parasites of the Indian Mackerel, Rastrelliger kanagurta (Scombridae) of Visakhapatnam Coast, Bay of Bengal. Journal of Parasitic Diseases, 35(1): 66-74.
Nelwan M. 2019. Schistosomiasis: Life cycle, diagnosis and control. Current Therapeutic Research, 91: 5-9.

Raissy M and Ansari M. 2012. Parasites of some freshwater fish from Armand River, Chaharmal va Bakhtyari Province, Iran. Iran Journal Parasitology, 7(1): 73-79.

Ruiz, G. 1991. Consequences of parasitism to marine invertebrates host evolution?. The American Society of Zoologists, 31(6): 831-893.

Sakthivel A, Selvakumar P and Gopalakrishnan. 2014. Acanthocephalan (Echinorhynchus sp.) infection of yellowfin tuna (Thunnus albacares) from Nagapattinam, south east coast of India. Journal of Coastal Life Medicine, 2(8): 596-600.

Salcedo N, Gonzaga E, Garduque R, Jimenez V and Panes T. 2009. Detection of common parasites in freshwater fish sold at the public market, Kabacan, Cotabato, Philippines. USM R\&D., 17(2): 147-149.

Skelly P. 2008. Sex and the Single Schistosome. Natural History, 117(5): 22-27

Velasquez C. 1984. Fish Parasitology and Aquaculture Management in the Philippines. National Academy of Science and Technology. 105-159.

Whitaker D and Kent M. 1991. Myxosporean Kudoa thyrsites: a cause of soft flesh in farm-reared Atlantic salmon. Journal of Aquatic Animal Health, 3: 291-294. 